\title{
FOXL2 activates $P 450$ aromatase gene transcription: towards a better characterization of the early steps of mammalian ovarian development
}

\author{
Maëlle Pannetier, Stéphane Fabre ${ }^{1^{*}}$, Frank Batista ${ }^{2^{*}}$, Ayhan Kocer, Lauriane Renault, \\ Geneviève Jolivet, Béatrice Mandon-Pépin, Corinne Cotinot, Reiner Veitia ${ }^{2}$ \\ and Eric Pailhoux
}

\author{
Biologie du Développement et de la Reproduction - UMR 1198 INRA-ENVA, Bât. J Poly, 78350 Jouy-en-Josas, France \\ ${ }^{1}$ Physiologie de la Reproduction et des Comportements - UMR 6175 INRA-CNRS-Université de Tours, Haras Nationaux, 37380 Nouzilly, France \\ ${ }^{2}$ INSERM U709 Génomique et Epigénétique des Pathologies Placentaires (Ex. U361), Hôpital Cochin, Pavillon Baudelocque, 123 Bd de Port Royal, 75014 Paris, France
}

(Requests for offprints should be addressed to E Pailhoux; Email: eric.pailhoux@jouy.inra.fr)

*(S Fabre and F Batista contributed equally to this work)

\begin{abstract}
Previous studies have equated FOXL2 as a crucial actor in the ovarian differentiation process in different vertebrate species. Its transcriptional extinction in the polled intersex syndrome (PIS) leads primarily to a drastic decrease of aromatase (CYP19) expression in the first steps of goat ovarian development. In this study, we provide a better characterization of early ovarian development in goat, and we provide experimental evidence demonstrating that FOXL2 represents a direct transcriptional activator of the CYP19 gene through its ovarian-specific promoter 2. Moreover, the ovarian location of FOXL2 and CYP19 proteins, together with their expression profiles in the female gonads, stress the involvement of FOXL2 co-factor(s) for regulating CYP19 transcription. Expressional analyses show that activin- $\beta A$ can be considered as a strong candidate for being one of these FOXL2 co-factors. Finally, we discuss evidence for a role of activin and estrogens in somatic and germinal cell proliferation occurring before germ cell meiosis. This period, of 20 days in goat, seems to have no equivalent in mouse. This species-specific difference could explain the phenotype discrepancy observed between XX goat $\mathrm{PIS}^{-/-}$and XX mouse Fox/2 ${ }^{-/-}$.
\end{abstract}

Journal of Molecular Endocrinology (2006) 36, 399-413

\section{Introduction}

Recent accumulating evidence indicates that the transcription factor FOXL2 is a crucial actor in early ovarian differentiation and maintenance. Natural mutations affecting FOXL2 have been shown to be involved in two syndromes leading to ovarian dysfunction in mammals. First, heterozygous mutations of FOXL2 induce premature ovarian failure in XX BPES (blepharophimosis-ptosis-epicanthus inversus syndrome) type I patients (Crisponi et al. 2001). Secondly, complete loss of ovarian expression of this gene was found to be associated with XX female-to-male sex-reversal in goats homozygous for the polled intersex syndrome (PIS) mutation (Pailhoux et al. 2001). As in humans, Foxl2 invalidation in mouse leads to premature ovarian failure, but only in the homozygous state (Schmidt et al. 2004, Uda et al. 2004). In Foxl2 null ovaries, granulosa cells fail to undergo squamous to cuboidal transition leading to arrest of folliculogenesis and oocyte atresia. During gonad development, FOXL2 displays an ovarian-specific expression profile. The female-specific expression profile

Journal of Molecular Endocrinology (2006) 36, 399-413

0952-5041/06/036-399 @ 2006 Society for Endocrinology Printed in Great Britain has been demonstrated in different mammalian species such as mouse (Pannetier et al. 2003), goat (Pannetier et al. 2005), and humans (Cocquet et al. 2002), but also in other vertebrates such as birds (Govoroun et al. 2004), turtles (Loffler et al. 2003) and fishes (Baron et al. 2004, Wang et al. 2004).

FOXL2 is a member of the forkhead/HNF-3-related gene family of transcription factors that are highly conserved and involved in many developmental processes and in cellular differentiation (for review see Carlsson \& Mahlapuu 2002). As the other member of the family, FOXL2 possesses a well-conserved winged helix domain that binds DNA to a 7-bp core recognition motif (5'-G/A-T/C-C/A-A-A-C/T-A-3') (Kaufmann \& Knochel 1996). Another feature of FOXL2 is the presence of a polyalanine domain of 14 alanines, located to the C-terminus with respect to the DNA binding domain. Although the physiological function of this polyalanine tract remains unknown, its expansion from 14 to 24 residues accounts for $30 \%$ of the reported mutations in BPES patients (De Baere et al. 2003). The 14 to 24 expansion induces extensive nuclear and 
cytoplasmic FOXL2 protein aggregation (Caburet et al. 2004). Until now, two FOXL2 target genes have been described in two different tissues, the gonadotropin releasing hormone receptor $(G n R H R)$ gene in the pituitary (Ellsworth et al. 2003) and the steroidogenic acute regulatory $(S t A R)$ gene in the adult ovary (Pisarska et al. 2004). Interestingly, the regulatory role of FOXL2 on these two targets appears to be different. While, FOXL2 contributes to a transcriptional activation of GnRHR, via the GRAS element (GnRH-receptor activating sequence), it leads to a transcriptional repression of StAR. Interestingly, in the developing ovary of chicken (Govoroun et al. 2004) and rainbow trout (Baron et al. 2004), the spatio-temporal expression profile of FOXL2 is strongly correlated with those of the CYP19 gene encoding aromatase, an enzyme responsible for the conversion of androgens into estrogens (for review see Conley \& Hinshelwood 2001). Then, one could hypothesize that the CYP19 gene may represent a direct target of FOXL2.

In non-mammalian species such as fishes, reptiles, and birds, estrogens have been shown to be crucial for proper ovarian differentiation. Consequently, male-tofemale sex reversal with the development of ovaries or ovotestes occurs after treatment with estradiol in male rainbow trout (Krisfalusi \& Cloud 1999), reed frog (Hayes \& Menendez 1999), reptiles (Pieau et al. 1999), and chicken (Scheib 1983). Conversely inhibition of estrogens, by the use of anti-aromatase, in embryos that would otherwise develop as females results in testis development in fishes (Guiguen et al. 1999), reptiles (Pieau et al. 1999) and birds (Elbrecht \& Smith 1992, Wade \& Arnold 1996). This crucial impact of estrogens in female gonad differentiation has also been demonstrated for different marsupial species, two opossums (Burns 1955, Fadem \& Tesoriero 1986) and the tammar wallaby (Coveney et al. 2001). In these metatherian mammals, estrogen treatment at the time of testis differentiation induces a male-to-female sex reversal.

In eutherian mammals, the role of estrogens in ovarian development is poorly documented. Indeed, hormonal treatments are not easy to perform because gonad differentiation takes place during fetal life in the maternal uterus. Moreover, the most studied model is the mouse, a species that has no ovarian steroidogenesis during fetal life. Accordingly, the major steroidogenic activator, steroidogenic factor $(S f-1)$, is not expressed in mouse ovaries from 13.5 days post-coïtum (dpc) to $18.5 \mathrm{dpc}$ (Ikeda et al. 1994). The absence of estrogen action on early ovarian development in the mouse is also confirmed by the absence of severe phenotypes in ovaries of newborn mice knocked-out for CIP19 (Fisher et al. 1998), StAR (Hasegawa et al. 2000), or estrogen receptors (ER $\alpha, \mathrm{ER} \beta)$ (Couse et al. 1999, Dupont et al. 2000).

By contrast with mouse, ovaries from domestic ruminants produce estrogens from the onset of their development. In sheep, ovaries are steroidogenically active at the time of morphological sexual differentiation as attested by direct hormonal dosages or CYP19 expression studies (Mauléon et al. 1977, Payen et al. 1996, Quirke et al. 2001). Interestingly, in XX sex-reversed PIS ${ }^{-/}$- goat fetuses, the first affected gene following FOXL2 extinction is CYP19 (Pailhoux et al. 2002, 2005). Indeed, CRP19 transcription is found drastically decreased in XX PIS ${ }^{-/-}$fetuses from 36 dpc, the earliest stage of its normal expression in goats. This decrease suggests that FOXL2 could play a direct regulatory role on CIP19 transcription.

In order to investigate further a putative enhancing effect of FOXL2 on CYP19 transcription, (i) immunolocalization of both proteins in goat fetal ovaries has been performed, (ii) the CYP19 promoter used in ovarian development has been determined, and (iii) a direct transcriptional effect of FOXL2 on CYP19 promoter 2 has been demonstrated by transfection assays in COS7 and granulosa cells. Furthermore, a direct interaction between FOXL2 and the promoter of CrP19 was also confirmed in a human granulosa cell line (KGN), by chromatin immunoprecipitation assay.

\section{Materials and methods}

\section{Animals and tissue samples}

All goat fetuses were obtained from horned pregnant females, following hormonal treatments as previously described (Pailhoux et al. 2002). Day 0 post-coitum corresponded to the day of mating. The genetic sex of all fetuses was determined by PCR amplification of SRY and $Z F Y / Z F X$ genes on liver genomic DNA (Pailhoux et al. 2002). For each fetus, one gonad was frozen in liquid nitrogen for molecular analysis; the other one was fixed for immuno-histological studies. For granulosa cell culture, ovine ovaries were collected from adult cyclic Romanov ewes from a local slaughterhouse for immediate use.

All procedures were approved by the agricultural and scientific research Government committees in accordance with the guidelines for the Care and Use of Agricultural Animals in Agricultural Research and Teaching in France (approval A37801).

\section{RT-PCR}

RNA extraction, DNase treatment, and cDNA synthesis were conducted as previously described (Pailhoux et al. 2001). Briefly, $2 \mu \mathrm{l}$ (corresponding to $0.5 \mu \mathrm{g}$ reverse transcribed total RNA) of each RT mix was amplified in $50 \mu \mathrm{l}$ PGR by using $0.5 \mathrm{U}$ Taq polymerase (TaKaRa), $200 \mu \mathrm{M}$ of each dNTP, and $150 \mathrm{nM}$ of each primer. The sequences of the primers used and the PGR conditions are given in Table 1. 
Table 1 Primers and PCR conditions

\begin{tabular}{|c|c|c|}
\hline \multirow[b]{2}{*}{ Primer names } & Primer sequences & Temp./MgCl2 \\
\hline & & \\
\hline Aromatase 1 (E9) & 5'-CTGTCGTGGACTTGGTCATG-3' & $58^{\circ} \mathrm{C} / 1.5 \mathrm{mM}$ \\
\hline Aromatase 2 (E10) & 5'-GGGGCCCAAAGCCAAATGGC-3' & \\
\hline 5'RACEAro1 & 5'-TGCAGGCACTGCCGATCCCC-3' & $58^{\circ} \mathrm{C} / 1.5 \mathrm{mM}$ \\
\hline 5'RACEAro2 & 5'-CAGTGGGAAATGAGGGGCCC-3' & \\
\hline 5'RACEAro3 & 5'-GAGGATGTGTCCTCATAATTCC-3' & \\
\hline 5'RACEAro4 (5A4) & 5'-GAAATCCAGTGAGCAGCAGG-3' & \\
\hline 5'RACEAro7 (5A7) & 5'-CAAAGCGCCAATCTCTACGG-3' & \\
\hline 5'RACEAro8 (5A8) & 5'-GTGGGAGACCTTGGTGCCTG-3' & \\
\hline 5'RACEAro9 (5A9) & 5'-GCCCTTCAAAGGACTTATCAC-3' & \\
\hline pAro1 & 5'-GTCCATGGGGTTGCAACGAG-3' & $58^{\circ} \mathrm{C} / 1.5 \mathrm{mM}$ \\
\hline pAro2 & 5'-CCAGCACATGGTGCAAGAG-3' & \\
\hline pAro3 & 5'-GAGAACTCAGTCACTCTACC-3' & \\
\hline pAro4 & 5'-CCTGAGACTCTACCAAGGTCA-3' & \\
\hline pAro5 & 5'-GACTCGTGACTATAAATTTG-3' & \\
\hline pAro-R & 5'-TTACTTGATCTCAGGGGAAG-3' & \\
\hline Inhibin- $\alpha-1$ & 5'-TGCCCCCTACCCСTTTCCAG-3' & $55^{\circ} \mathrm{C} / 1.5 \mathrm{mM}$ \\
\hline Inhibin- $\alpha-2$ & 5'-CTTAGATGCAAGCACAGTGC-3' & \\
\hline Activin- $\beta A-1$ & 5'-GGCAAGGTCAACATTTGCTG-3' & $55^{\circ} \mathrm{C} / 1.5 \mathrm{mM}$ \\
\hline Activin- $\beta A-2$ & 5'-ACATGGACATGGGTCTCAGC-3' & \\
\hline Activin- $\beta$ B-1 & 5'-GAGTCGCACCGGCCCTTCGT-3' & $58^{\circ} \mathrm{C} / 1.5 \mathrm{mM}$ \\
\hline Activin- $\beta$ B-2 & 5'-CCCATAGTAGCCGGTGGGCG-3' & \\
\hline ActRII-1 & 5'-AACGAGGCACCAGTGTTGAT-3' & $60^{\circ} \mathrm{C} / 1.5 \mathrm{mM}$ \\
\hline ActRII-2 & 5'-AGTACAGCGAGAAGCCAGTT-3' & \\
\hline $3 \beta \mathrm{HSD}-1$ & 5'-CTCGTGACCGGAGGAGGAGG-3' & $58^{\circ} \mathrm{C} / 1.5 \mathrm{mM}$ \\
\hline $3 \beta \mathrm{HSD}-2$ & 5'-GCTGGAAATAGTGAGCTTCC-3' & \\
\hline $\mathrm{ER} \alpha-1$ & 5'-CTTCCCGCCGCTCAACAGCG-3' & $67^{\circ} \mathrm{C} / 1.5 \mathrm{mM}$ \\
\hline$E R \alpha-2$ & 5'-CTCTCTGGCGCTTGTGCTTC-3' & \\
\hline$E R \beta-1$ & 5'-GACATGCTCCTGGCAACGAC-3' & $55^{\circ} \mathrm{C} / 1.5 \mathrm{mM}$ \\
\hline$E R \beta-2$ & 5'-GCAGGTGTTCCATGCCCTTG-3' & \\
\hline FOXL2-9 & 5'-GGCCCCCTGAGCCAGCGCCC-3' & $58^{\circ} \mathrm{C} / 1.5 \mathrm{mM}$ \\
\hline FOXL2-10 & 5'-CCCCGACGCTGAGGTGCCCG-3' & \\
\hline SP011-Cup & 5'-TGCAACATTTCAGCGGCTCC-3' & $56^{\circ} \mathrm{C} / 2.0 \mathrm{mM}$ \\
\hline SPO11-Ddown & 5'-TCAGAAGGGAGRAGACCAAG-3' & \\
\hline$\beta$-actin-1 & 5'-CATCCGTAAAGACCTCTATGCC-3' & $55^{\circ} \mathrm{C} / 2.5 \mathrm{mM}$ \\
\hline$\beta$-actin-2 & 5'-TAGAGCCACCAATCCACACAG-3' & \\
\hline ChIP-CYP19up & 5'-AACCTGCTGATGAAGTCACAA-3' & $54^{\circ} \mathrm{C} / 2.5 \mathrm{mM}$ \\
\hline ChIP-CYP19down & 5'-TCAGACATTTAGGCAAGACT-3' & \\
\hline ChIP-IMP3up & 5'-AGTTGTTGTCCCTCGTGACC-3' & $54^{\circ} \mathrm{C} / 2.5 \mathrm{mM}$ \\
\hline ChIP-IMP3down & 5'-GTCCACTTTGCAGAGCCTTC-3' & \\
\hline ChIP-G3PDHup & 5'-ACCACAGTCCATGCCATCAC-3' & $54^{\circ} \mathrm{C} / 2.5 \mathrm{mM}$ \\
\hline ChIP-G3PDHdown & 5'-TCCACCACCCTGTTGCTGTA-3' & \\
\hline
\end{tabular}

\section{Rapid amplification of cDNA ends (RACE)}

To determine the CIP19 promoters used in the goat ovary, 5' RACE experiments were carried out on $5 \mu \mathrm{g}$ DNase-treated total RNA purified from goat ovaries at two developmental stages (1 month old and adult). Reverse transcription of CYP19 specific RNA was performed by using the primer $5^{\prime}$ RACEArol (Table 1). Reverse transcription assays and PCR amplifications were performed using the $5^{\prime}$ RACE system from GibcoBRL, according to the manufacturer's instructions. Briefly, two rounds of PCR using nested primers were carried out. The first round of PCR was performed with 5'RACEAro2, the second round with either 5'RACEAro3 or 5'RACEAro4 (Table 1). All these 4 primers were located in exons 2 and 3 of CTP19 that are present in all mRNA isoforms. They were designed from the goat CYP19 mRNA sequence (Genbank accession number AY148883). The PCR products obtained after the second round of PCR and showing a $34 \mathrm{bp}$ difference in size, which is the length present between the two primers used, 5'RACEAro3 and 5'RACEAro4, were cloned. Then, at least three independent clones per PCR product were sequenced.

\section{Plasmid constructs}

Different lengths of CYP19 promoter 2 fragments were obtained by PCR using pAro1, pAro2, pAro3, pAro4 or 
pAro5 as forward primers, and pAro- $\mathrm{R}$ as reverse primer (Table 1). These different promoters were cloned upstream of the luciferase gene in the pGL3-basic vector (Promega). Goat FOXL2 ORF was obtained by PGR and inserted in the pSG5 vector (Stratagene) as previously described (Govoroun et al. 2004). Constructions 3 xGRAS-Luc and Foxl2-VP16 were gratefully obtained from Dr Clay's laboratory (Ellsworth et al. 2003). All plasmids were amplified in DH5 $\alpha$ bacteria, and large amounts of plasmids were obtained by using the anion exchange columns nucleobond AX (Macherey-Nagel, Düren, Germany).

\section{Cell culture conditions and transfection assays in cos7 cells}

COS7 cells were cultured in Dulbecco's modified Eagle's medium and Ham's F-12 medium (Eurobio, Courtaboeuf, France) containing $10 \% \quad(\mathrm{v} / \mathrm{v})$ heatinactivated fetal calf serum, penicillin $(100 \mathrm{U} / \mathrm{ml})$, streptomycin $(100 \mu \mathrm{g} / \mathrm{ml})$ and L-glutamine $(300 \mu \mathrm{g} / \mathrm{ml})$, in a $5 \% \mathrm{CO}_{2}$ atmosphere at $37^{\circ} \mathrm{C}$. For transfection, $1.3 \times 10^{5}$ cells were seeded in 12 -well Petri dishes and transfected the following day using FuGENE 6 reagent (Roche), according to the manufacturer's instructions. The amount of transfected DNA was $1 \mu \mathrm{g}$ of the reporter vectors with $0 \cdot 25 \mu \mathrm{g}$ Foxl2-VP16 or pVP16 alone (negative control). Each combination of plasmids was tested in triplicate in each culture and in three independent experiments. Seventeen hours after transfection, cells were harvested by scraping in $1 \mathrm{ml}$ PBS, pelleted by centrifugation and resuspended in $50 \mu \mathrm{l}$ lysis buffer (25 mM glycylglycine, $1 \mathrm{mM}$ EDTA, $8 \mathrm{mM}$ $\mathrm{MgSO}_{4}, 1 \%$ Triton, $15 \%$ glycerol, $1 \mathrm{mM}$ dithiothreitol). A $10 \mu$-extract was used for the measurement of luciferase activity. Each tube of extract was placed in a luminometer equipped with one reagent injector (Berthold, Bad Wildbad, Germany), and the reaction was initiated by the injection of $100 \mu \mathrm{l}$ substrate solution containing $23 \mu \mathrm{l}$ luciferine $(1 \mathrm{nM})$ and $77 \mu \mathrm{l}$ of its buffer

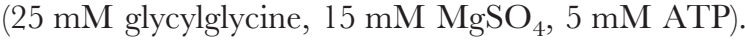

\section{Ovine granulosa cells (OGC) primary culture and transfection assays}

In each independent culture experiment, ovarian follicles from three Romanov ewes were quickly dissected, pooled and classified according to size. Ovine GG were recovered from small antral follicles $(1-3 \mathrm{~mm}$ in diameter) as previously described (Le Bellego et al. 2002). They were seeded at 200000 cells/well in 24-well plates and cultured in McCoy's 5a medium (Sigma, L'Isle d'Abeau Chesnes, France) supplemented with 3\% fetal ovine serum. After $48 \mathrm{~h}$, the medium was changed and oGG were transiently transfected as previously described (Pierre et al. 2004) using DAC30 transfection reagent with a DNA/DAC30 ratio of $1 / 2(w / w)$ as specified by the manufacturer (Eurogentec, Seraing, Belgium). Ovine GG were transfected with pARO or GRAS luciferase reporter genes (250 ng/well) both alone or in combination with plasmids expressing goat FOXL2 or mouse Foxl2-VP16 (250 ng/well). Empty pSG5 or pVP16 plasmids were used in control conditions. After $48 \mathrm{~h}$, cells were lyzed before the luciferase assay (Promega, Charbonnières, France). Each combination of plasmids was tested in triplicate in each culture and in three independent experiments.

\section{Chromatin immunoprecipitation}

To perform the chromatin immunoprecipitation (ChIP) assay, KGN cells (Nishi et al. 2001) were grown to confluence in DMEM-F12 medium supplemented with 10\% FBS. Formaldehyde cross-linked cells were scraped into a conical tube in $2 \mathrm{ml}$ PBS supplemented with protease inhibitors $(1 \mathrm{mM}$ PMSF, $1 \mu \mathrm{g} / \mathrm{ml}$ aprotinin, $1 \mu \mathrm{g} / \mathrm{ml}$ pepstatin), centrifuged for $4 \mathrm{~min}$ at $500 \mathrm{~g}$, and the cell pellet was resuspended in $10^{6}$ cells per $200 \mu \mathrm{l}$ SDS lysis buffer (Upstate Biotechnology, Lake Placid, NY, USA, ChIP assay kit). Resuspended cells were sonicated five times for $20 \mathrm{~s}$, with pauses of $30 \mathrm{~s}$ between each sonication round. The sonicated supernatant was diluted to $1 \mathrm{ml}$ in RIPA buffer without SDS $(300 \mathrm{mM} \mathrm{NaCl}, 10 \mathrm{mM}$ Tris-HCl $\mathrm{pH} 7 \cdot 4,5 \mathrm{mM}$ EDTA and $1 \% \mathrm{NP} 40)$. To reduce nonspecific background, samples were pre-cleared for $2 \mathrm{~h}$ at $4{ }^{\circ} \mathrm{C}$ using pre-immune serum and $7 \cdot 5 \%$ protein A-sepharose gel in RIPA buffer with protease inhibitors. Pre-cleared extracts were then incubated overnight in the presence of either $1 \%$ pre-immune serum (negative control) or with the anti-C terminal FOXL2 antibody previously described (Cocquet et al. 2002). Washes and the rest of the experiment were carried out according to the protocol from the Upstate Biotechnology kit. In order to exclude a potential contamination with non-specifically adsorbed DNA, we attempted to amplify insulin-like growth factor II mRNA-binding protein 3 (IMP3) and glyceraldehyde-3-phosphate dehydrogenase (G3 PDH) genes, which are not supposed to be targets of FOXL2. This was performed on both the material immunoprecipitated with the pre-immune serum (negative control), and with the anti-FOXL2 antibody. The sequences of the primers used in the PCRs are indicated in Table 1. CTP19 primers have been described previously (Ghosh et al. 2005). PGR conditions were as follows: $94{ }^{\circ} \mathrm{C}$ for $5 \mathrm{~min}, 30$ cycles of $94{ }^{\circ} \mathrm{C}$ for $30 \mathrm{~s}, 54^{\circ} \mathrm{C}$ for $30 \mathrm{~s}, 72^{\circ} \mathrm{C}$ for $40 \mathrm{~s}$, and then $72{ }^{\circ} \mathrm{C}$ for $5 \mathrm{~min}$. Taq polymerase was purchased from Invitrogen.

\section{In situ hybridization}

The cDNA used for riboprobe synthesis was obtained by RT-PCR on goat adult ovary with $3 \beta$ hydroxysteroid 


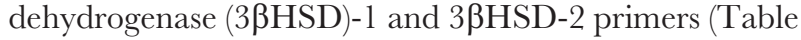
$1)$, and then subcloned into pGEM-T Easy vector. Riboprobes were generated by transcription in the presence of digoxygenin-labeled deoxy-UTP and the appropriate SP6 or T7 RNA polymerase. Freshly dissected goat ovaries were fixed for $1 \mathrm{~h}$ in $4 \%$ paraformaldehyde in phosphate saline buffer (PBS) at $4{ }^{\circ} \mathrm{C}$. After washing in PBS with increasing concentrations of sucrose $(0,12 \%$, $15 \%$, and $18 \%$ ), tissue specimens were embedded in Jung tissue freezing medium (Leica Instruments, Wetzlar, Germany) and frozen at $-80^{\circ} \mathrm{C}$. Sections $(7 \mu \mathrm{m}$ thick $)$ were produced and stored at $-80^{\circ} \mathrm{C}$. After thawing, frozen sections were de-lipidized in chloroform for $1 \mathrm{~min}$, and re-hydrated in PBS. Then, sections were post-fixed for 20 min with $2 \%$ paraformaldehyde in PBS, $\mathrm{pH} 9$, and treated for $10 \mathrm{~min}$ in $0 \cdot 25 \%$ acetic anhydride in $0 \cdot 1 \mathrm{M}$ triethanolamine, $\mathrm{pH} 8$. After $2 \mathrm{~h}$ prehybridization in 50\% formamide, $2 \times$ sodium saline citrate, $5 \times$ Denhardt's solution, $50 \mu \mathrm{g} / \mathrm{ml}$ yeast tRNA, $250 \mu \mathrm{g} / \mathrm{ml}$ salmon sperm DNA, 4 mM EDTA and $2.5 \%$ dextran sulfate at $55^{\circ} \mathrm{C}$, hybridization was carried out overnight at $55^{\circ} \mathrm{C}$ in a moist chamber with riboprobes diluted in the same buffer without salmon sperm and EDTA. The slides were washed twice in $2 \times \mathrm{SSC}$ and were then treated for $30 \mathrm{~min}$ at $37^{\circ} \mathrm{C}$ with ribonuclease $\mathrm{A}(20 \mathrm{mg} / \mathrm{ml})$ in NTE $(500 \mathrm{mM}$ NaCl, $10 \mathrm{mM}$ Tris-HCl pH 7.5, $5 \mathrm{mM}$ EDTA). After 4 washings in $2 \times \mathrm{SSC}$, slides were incubated for $1 \mathrm{~h}$ in $0 \cdot 1 \times \mathrm{SSC}, 30 \%$ formamide at $60{ }^{\circ} \mathrm{C}$. Then sections were washed for $1 \mathrm{~h}$ in Tris $\mathrm{pH} 7 \cdot 5$ $100 \mathrm{mM}$, NaCl $150 \mathrm{mM}, 0 \cdot 5 \%$ blocking reagent (Roche), and incubated with an alkaline phosphatase anti-DIG antibody (Roche) (diluted 1/500) in the same buffer. After 3 washes with $100 \mathrm{mM}$ Tris $\mathrm{pH} 7 \cdot 5,150 \mathrm{mM} \mathrm{NaCl}$, slides were rinsed for 20 min with alkaline phosphatase buffer $(100 \mathrm{mM}$ Tris $\mathrm{pH} 9 \cdot 5,100 \mathrm{mM} \mathrm{NaCl}, 50 \mathrm{mM}$ $\mathrm{MgCl}_{2}$ ) and incubated overnight with the staining solution NBT/BCIP Ready-to-use tablets (Roche) containing $0.24 \mathrm{mg} / \mathrm{ml}$ of levamisole (Sigma). The reaction was stopped with water and slides were mounted in glycerolgelatin medium (Sigma).

\section{Immunostaining}

Sections were air dried and re-hydrated in PBS. FOXL2 anti-C terminal antibody $(1 / 500$ or $1 / 1000)$, P450aromatase (1/50, Serotec), $\alpha$-inhibin (1/100, Serotec), $\beta A$-activin $(1 / 200$, Serotec, Oxford, UK), c-Kit (1/50, Santa Cruz Biotechnology, Santa Cruz, CA, USA), ER $\alpha$ (1/50, Santa Cruz Biotechnology) or ER $\beta$ (1/200, Upstate biotechnology) were then applied onto the tissue sections for $1 \mathrm{~h}$ at room temperature. After three washings, sections were incubated with biotinylated anti-rabbit secondary antibody (1/200, VECTOR, Burlingame, GA, USA) (FOXL2, c-Kit, ER $\alpha$ and ER $\beta$ ) or biotinylated anti-mouse secondary antibody $(1 / 200$, VECTOR) (P450-aromatase, inhibin- $\alpha$ and activin- $\beta$ A) for 30 min at room temperature and rinsed in PBS. An ABC system (VECTOR) was then applied to sections for 30 min. After three washes with PBS, peroxidase activity was revealed with 3,3'-diaminobenzidine (VECTOR). Slides were rinsed and permanently mounted in EUKKIT (Sigma) mounting medium.

For double immunostaining, FOXL2 staining was followed by $\mathrm{P} 450$-aromatase staining. Peroxidase activity was revealed with VECTOR-SG substrate (VEGTOR) for FOXL2 and with DAB for P450-aromatase.

\section{Histological processing}

Freshly dissected gonads were fixed in Bouin's fluid for $24 \mathrm{~h}$, dehydrated, embedded in paraffin and sectioned at $7 \mu \mathrm{m}$. Sections were mounted and stained according to the trichrome technique of Tuchmann du Plessis.

\section{Results}

\section{FOXL2 and CYP19 co-localize in the same cellular type of goat $\mathbf{4 5} \mathrm{dpc}$ ovaries}

In order to test if FOXL2 could act as a modulator of CYP19 gene expression, we first examined the cellular localization of both proteins in the developing ovary by immunohistochemistry. In addition, $3 \beta$-HSD mRNAs, encoding a crucial enzyme of steroid biosynthesis, were detected by in situ hybridization (Fig. 1). The experiments were performed at the $45 \mathrm{dpc}$ stage, when the higher levels of CIP19 transcripts were detected by RT-PGR (Fig. 2B). As previously shown, at $36 \mathrm{dpc}$ (Cocquet et al. 2002) FOXL2 was detected in the majority of somatic cells in the $45 \mathrm{dpc}$ ovaries (Fig. 1G,E). However, no signal was detected either in the region located just below the surface epithelium or in the germ cells, which were concentrated in this region. On the other hand, CYP19 protein and $3 \beta-H S D$ mRNA were found expressed by somatic cells located in the deeper medulla part of the ovary (Fig. 1A,B). By a double immunostaining approach, it appeared that all CYP19-expressing cells were also positive for FOXL2, but there were many cells positive for FOXL2 that did not express aromatase (Fig. 1E,F). These results indicated that FOXL2 could represent a direct transcriptional activator of CYP19. However, FOXL2 is not sufficient alone to trigger fetal CYP19 expression, as some FOXL2-positive cells do not express GYP19.

\section{CYP19 is transcribed via its promoter 2 during goat fetal ovarian development}

In human and bovine, the CYP19 gene uses different tissue-specific promoter regions to transcribe different non-coding first exons (named $1 \cdot 1,1 \cdot 2,1 \cdot 3$,...etc; and 2 ) 


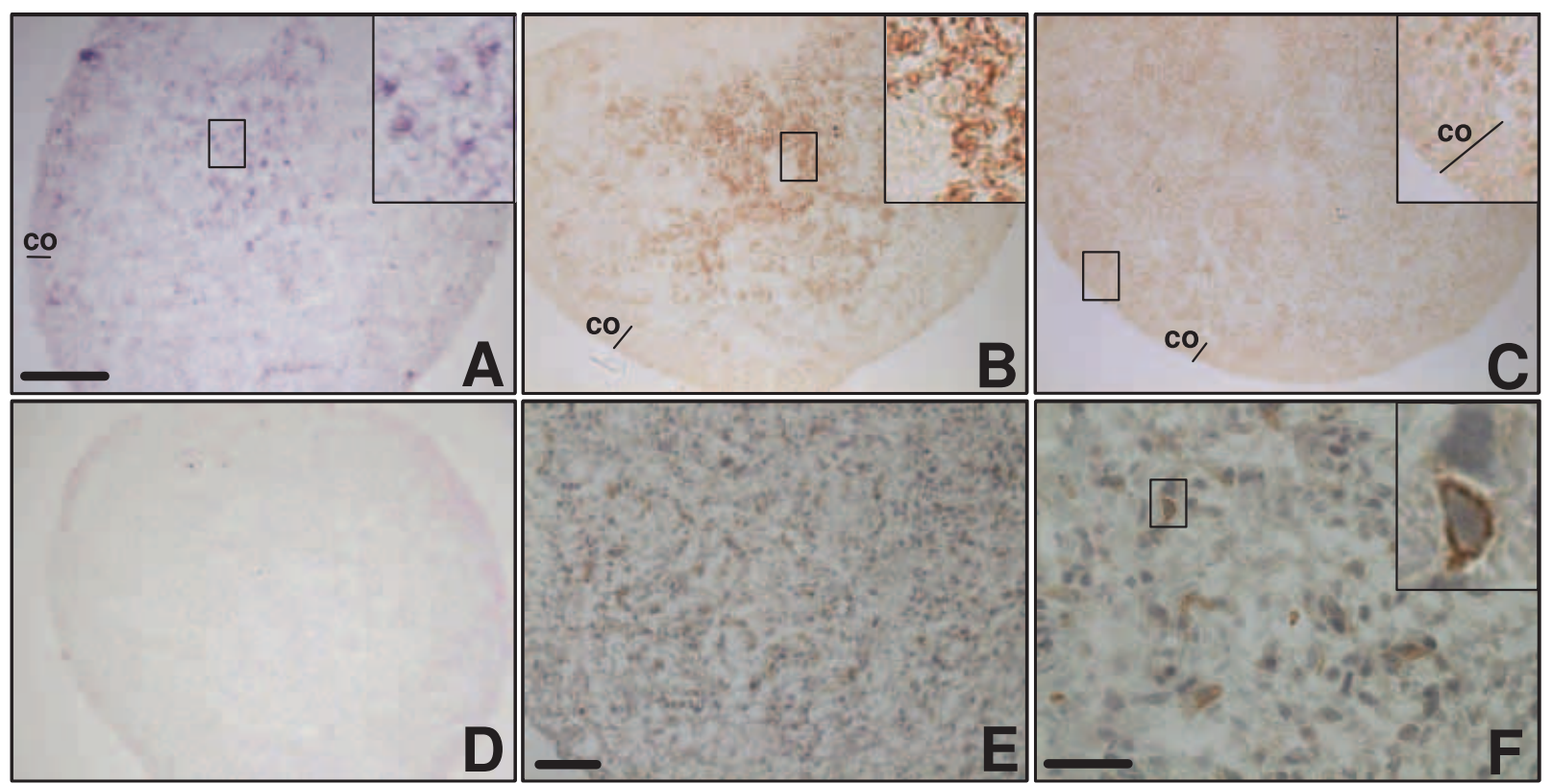

Figure $13 \beta-H S D$, FOXL2 and CYP19 expression in a 45 dpc goat ovary. (A) 3 $\beta$-HSD mRNA detected by in situ hybridization. (B) CYP19 protein and (C) FOXL2 protein detected by immunohistochemistry. (E and F) Double immunolocalization of FOXL2 (blue nuclear staining) and CYP19 (brown cytosolic staining). Note that all CYP19 positive cells also expressed FOXL2. (D) Negative control, sense probe for $3 \beta-H S D$. Higher magnification $(\times 4)$ of a positive region (inside the rectangle) is presented for $A, B, C$ and $F$ in the upper right corner. A line represents the thinness of the cortical region (co) where the majority of germ cells are located. Scale bar in A (for A-D), $200 \mu \mathrm{m}$, scale bars in E and F, $50 \mu \mathrm{m}$.

(Furbass et al. 1997, Bulun et al. 2004). In bovine, a species closely related to goat, CYP19 promoter 2 (located in front of exon 2, the first coding exon) has been shown to be used mainly in adult ovaries (Furbass et al. 1997). In order to determine the promoter used in fetal goat ovaries, and to test its putative responsiveness to FOXL2, we carried out 5' RACE experiments on CYP19 transcripts from ovarian goat samples at 30 days post-partum (dpp) and at adulthood. In both cases, 5' RACE-products, ranging from $0 \cdot 15$ to $0.35 \mathrm{~kb}$ in length, were detectable after the second round of PCR. Each band was cloned independently and three clones of each were sequenced. Two and three different alternative first exons were detected at $30 \mathrm{dpp}$ and adulthood respectively (Fig. 2A). At 30 dpp, transcripts corresponding to a transcriptional initiation at promoter $2 \mathrm{a}$ (promoter 2, distal TATA box) and a newly characterized promoter $1 \cdot 6$, located at $\sim 850 \mathrm{bp}$ upstream from the ATG initiator codon on the goat sequence, were isolated. At the adult stage, transcripts generated from promoters 2a, 2b (promoter 2, proximal TATA box), and $1 \cdot 1$ were isolated. Promoter $1 \cdot 1$ has previously been shown to be used mainly in bovine placenta (Furbass et al. 1997). The presence of two TATA boxes, separated by $28 \mathrm{bp}$ in the promoter 2, can also be seen for the bovine and the ovine species (Furbass et al. 1997, Vanselow et al. 1999).
The use of the different ovarian promoters isolated by RACE, together with promoter 1.5 previously described in sheep (Vanselow et al. 1999), were then tested on developing ovaries mRNAs by promoter-specific RTPCR (Fig. 2B). The promoter-specific expression profiles obtained were compared with the one obtained with primers located in exons 9 and 10, which are able to detect all CYP19 transcripts (Fig. 2B). In this way, no transcripts initiated from promoters 1.6 and 1.5 can be detected after 35 PCR cycles (data not shown). Transcripts initiated from promoter $1 \cdot 1$ were detected at 40 dpp and in the adult, in agreement with results recently published in a bovine species (Lenz et al. 2004). More interestingly for our purpose, only the promoter 2 seems to be used in the developing goat ovaries before the onset of germ cell meiosis ( $55 \mathrm{dpc}$ ), as attested by the expression profile of the meiosis-specific gene SPO11 (Fig.2B). Indeed, CYP19 expression profiles were found to be highly similar when detected with primers located in exons 9 and 10 (present in all transcripts), or when detected in the $5^{\prime}$ non-coding region of exon 2 , specifically present in transcripts generated from promoter 2 . Furthermore, the fact that FOXL2 expression profile did not peak as did those of CYP19 before germ cell meiosis, reinforces the idea that FOXL2 is not sufficient alone to trigger fetal CYP19 expression (Fig. 2B). 
A

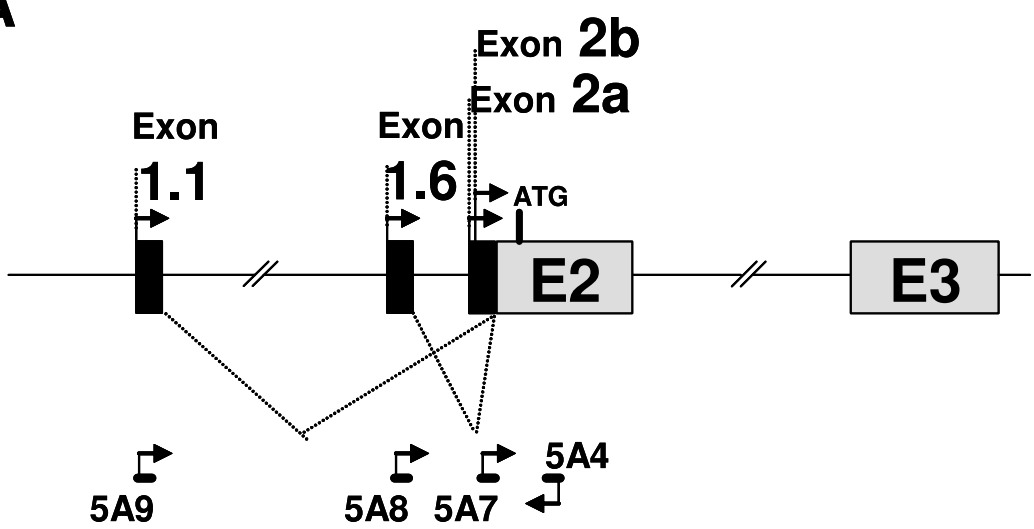

B

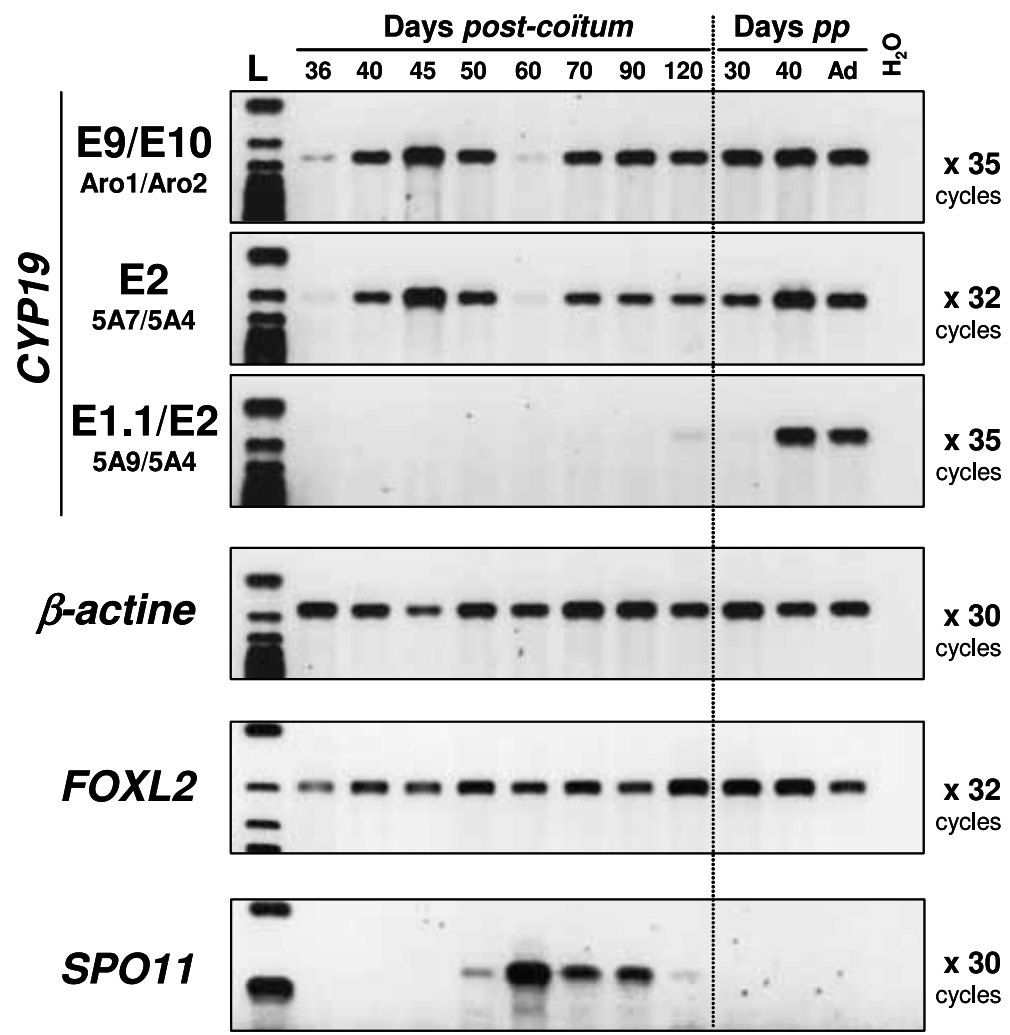

Figure 2 CYP19 promoters used during goat ovarian development. (A) Schematic representation of the three different promoter regions found by 5' RACE analyses; two distal promoters transcribed exon 1.1 and exon 1.6, and one proximal promoter, with two TATA boxes, transcribed directly exon 2 (exon $2 a=$ distal TATA box, exon $2 \mathrm{~b}=$ proximal TATA box). Promoter specific primers $(5 \mathrm{~A} 9,5 \mathrm{~A} 8,5 \mathrm{~A} 7)$ located in the different $5^{\prime}$ non-coding exons are indicated, with the reverse one (5A4) located in the common coding part of the different CYP19 transcripts. (B) RT-PCR expression studies of aromatase tested for all transcripts, with primers located in exons 9 and 10 (E9/E10) or for transcripts specifically initiated at promoters 1.1 or 2, compared with expression profiles of FOXL2 and SPO11, a meiosis-specific factor. E, exon; Days $\mathrm{pp}$, days post partum. 
A
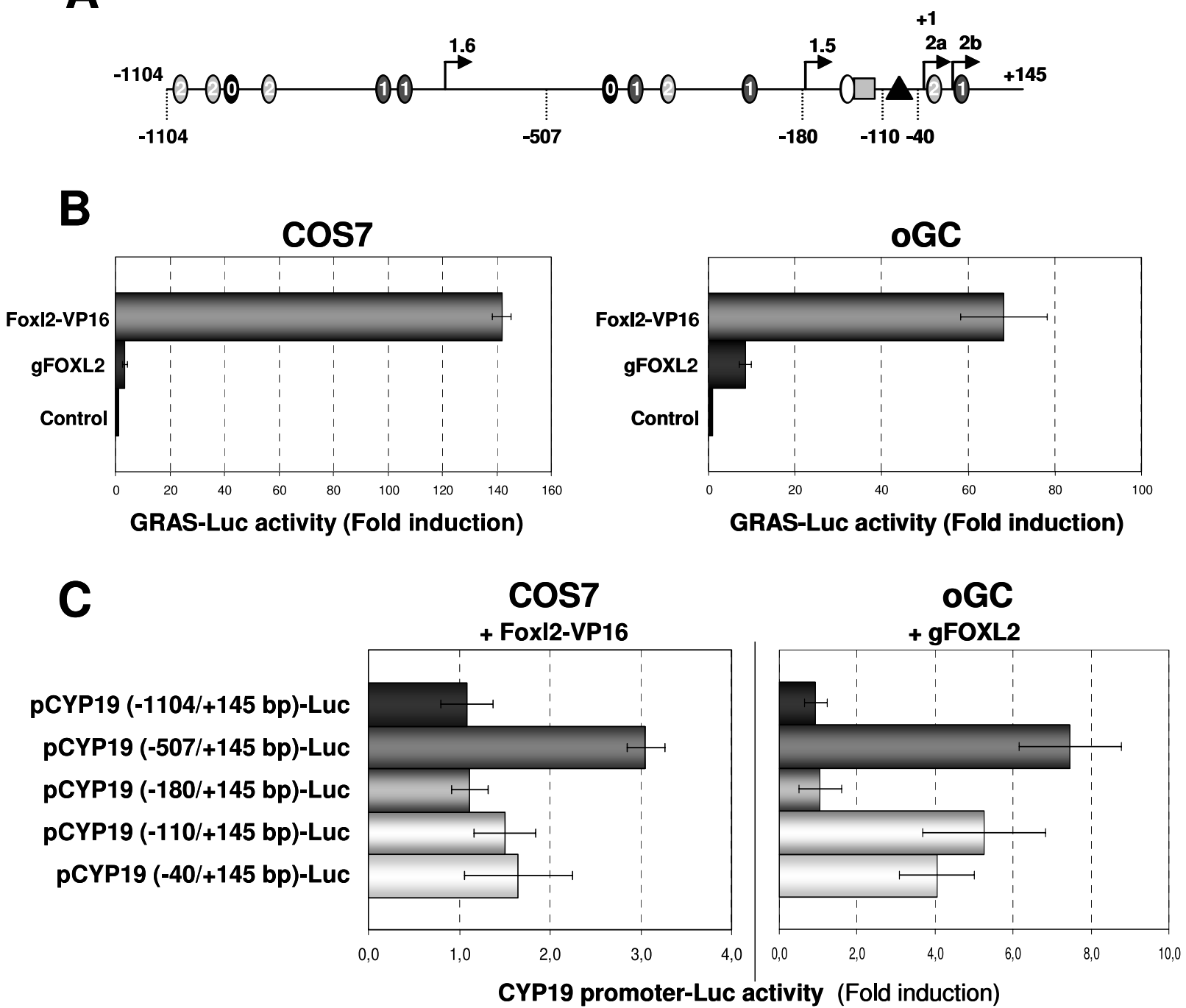

Figure 3 Transfection assays. (A) Schematic representation of the 1249 bp fragment encompassing CYP19 promoters 2 (2a, $2 \mathrm{~b}), 1.5$ and 1.6. Circles represent the putative FOXL2 binding sites with no mismatches (black with a 0 inside), one mismatch (dark gray with a 1 inside) or two mismatches (light gray with a 2 inside) in the first three bases of the consensus. The putative Smad-binding site (gray square) near a FOXL2 degenerated site (empty circle) and the putative HNF3/FOXQ1 (black triangle) are also indicated. The location of the $5^{\prime}$ bases of the five different restricted CYP19 promoters cloned in front of the luciferase reporter gene are indicated by dotted lines $(-1104,-507,-180,-110$, and -40$)$. (B) Comparative induction test of native goat FOXL2 (gFOXL2) and chimerical Foxl2-VP16 on the reporter construct containing three copies of the GRAS element cloned in front of the prolactin promoter driving the luciferase gene. (C) Multiple analyses of luciferase reporter gene driven by different fragments of CYP19 promoter. The different plasmid constructs (pCYP19-Luc) are indicated in the left margin. In COS7 cells, plasmid constructs were transiently co-transfected with a FoxI2-VP16 expression vector or VP16 vector alone. In sheep granulosa cells (oGC) plasmid constructs were transiently co-transfected with a gFOXL2 expression vector or pSG5 vector alone. In both cases, cells were harvested and assayed for luciferase activity. Results are presented as fold induction obtained with Foxl2-VP16 or gFOXL2 compared with VP16 alone or pSG5 alone, in COS7 or oGC respectively.

\section{FOXL2 is an inductor of the CYP19 promoter 2}

To determine if the CIP19 promoter 2, used in $45 \mathrm{dpc}$ goat ovaries, could represent a direct target of FOXL2, a 1249 bp fragment encompassing promoter 2 has been isolated by PCR from goat genomic DNA (Genbank accession number DQ122857). This fragment contained respectively $1104 \mathrm{bp}$ upstream and $145 \mathrm{bp}$ downstream of the transcriptional start site of promoter $2 \mathrm{a}(+1)$ and encompassed three putative CIP19 promoters, $1 \cdot 6,1 \cdot 5$ and 2 (Fig. 3A). Based on the FOX recognition 7-bp motif (5'-G/A-T/C-C/A-A-A-C/T-A-3') (Kaufmann \& 
Knochel 1996), the core of this motif (A-A-Y-A) was searched on this goat fragment. Among twelve detected sites, 2 presented no mismatch, 5 had one mismatch and 5 two mismatches compared with the consensus sequence (Fig. 3A). Moreover, one HNF-3/FOXQ1 (position $-50 /-44$ ), and one putative binding site for the Smad factors linked to a degenerated site for the FOX family position $(-128 /-114)$ have been pointed out by the Genomatix MatInspector software (http:// www.genomatix.de).

In order to delineate the putative FOXL2 responsive elements in the $1249 \mathrm{bp}$ of the goat CYP19 promoter, a successive deletion approach was used. Different $5^{\prime}$-ends of the promoter 2 were cloned upstream of the luciferase reporter gene and transiently transfected alone or in combination with FOXL2-expressing vectors in COS7 cells as well as in primary oGG. First of all, using the GRAS-containing reporter construct previously shown to be a Foxl2 target in the mouse (Ellsworth et al. 2003), we have tested the functionality of the goat FOXL2 protein (gFOXL2) compared with the already described (Ellsworth et al. 2003) mouse Foxl2-VP16 fusion protein. As indicated in Fig. 3B, Foxl2-VP16 was able strongly to activate the GRAS construct in COS7 cells as well as in oGG. However, gFOXL2 appeared to be functional preferentially in oGC, which suggests that a natural FOXL2 co-factor is missing in the COS7 cells. Based on these results, goat CYP19 promoter constructs were tested for Foxl2-VP16 action in COS7 cells and for gFOXL2 action in oGG.

In COS7 cells, a threefold induction of luciferase activity was seen with Foxl2-VP16 on the $-507 /+145$ CYP19 promoter construct (Fig. 3B). This induction was lost after a further deletion $(-180 /+145)$, indicating a major role of the 327-bp region between -180 and -507 , containing four putative FOXL2 binding sites. Interestingly, the same result was observed in oGC for gFOXL2 activity. However, in this closer physiological system, the sensitivity of the goat CIP19 promoter to gFOXL2 was much higher as shown by the $7 \cdot 5$-fold induction on the $-507 /+145$ construct. By contrast, Foxl2-VP16 was unable to activate this construct $(0 \cdot 61$ $\pm 0 \cdot 05$-fold induction). Moreover, the luciferase activity noticed for the smallest constructs was also significantly induced by gFOXL2 in oGC, indicating a possible role on the proximal part of promoter $2(-40 /+145)$ where two putative FOXL2 binding sites were located.

In order to verify that FOXL2 directly interacts with the CIP19 promoter we have carried out a chromatin immunoprecipitation assay in a human granulosa cell line (KGN), by using the FOXL2 anti-C terminal antibody. A parallel immunoprecipitation was carried out with the pre-immune serum (negative control). Figure 4 shows that, on the one hand, markers like IMP3 and G3 PDH, which are not supposed to be targets of FOXL2, cannot be amplified from the DNA of the chromatin

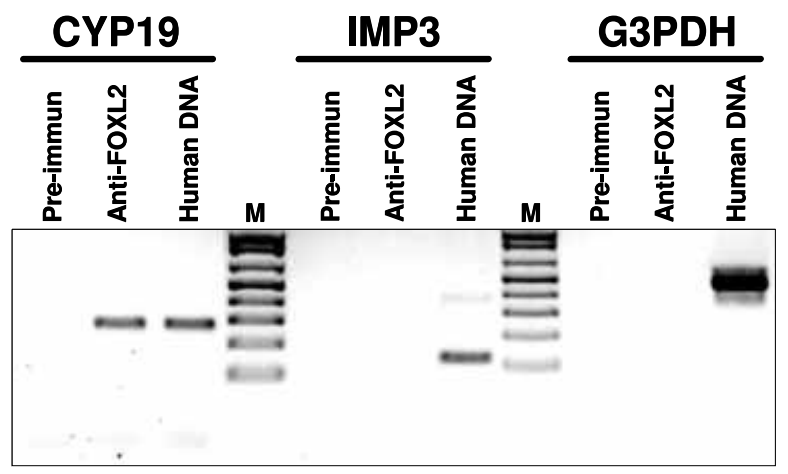

Figure 4 Chromatin immunoprecipitation assay. Amplification of the CYP19 promoter was positive only in the chromatin immunoprecipitated with the anti-FOXL2 antibody. No signal was detected with the pre-immune serum. We failed to amplify DNA fragments from IMP3 and G3 PDH genes, not supposed to be targets of FOXL2, which excludes a potential non-specific chromatin adsorption. Human DNA stands for the positive control of PCR.

immunoprecipitated by the anti-FOXL2 antibody. This is also true for the precipitation in the presence of the pre-immune serum. This shows that non-specific chromatin adsorption was negligible in our conditions of immunoprecipitation and washing. On the other hand, strong PCR amplification was obtained with primers specific for the ovarian promoter of CYP19. These primers amplified a 260 bp fragment located just upstream of the distal TATA box. As expected, no amplification was obtained when the pre-immune serum was used in the precipitation. We also tested a pair of primers specific for the CYP19 ORF and no amplification was obtained in any case, showing that the precipitated chromatin contained specifically the granulosa-specific promoter region of the gene. We repeated this assay three independent times and the results were always the same.

In conclusion, altogether these results indicate that FOXL2, by its co-localization with aromatase, its positive action on CIP19 promoter and its direct interaction with the latter can act as a direct transcriptional regulator of the CYP19 gene expression. However, (i) the existence of FOXL2 expressing cells, negative for CYP19 expression, (ii) the observed decrease of CTP19 expression at $60 \mathrm{dpc}$ while FOXL2 expression remains stable and, (iii) the fact that gFOXL2 functions preferentially in its normal cellular context, i.e. granulosa cells, are key indicators of the existence of FOXL2 co-factors necessary to fully control CYP19 transcription during ovarian development.

\section{Activin- $\beta A$ is a good candidate for being a FOXL2 co-factor}

Due to the increasing impact of numerous members of the TGF $\beta$ (transforming growth factor) family on ovarian 


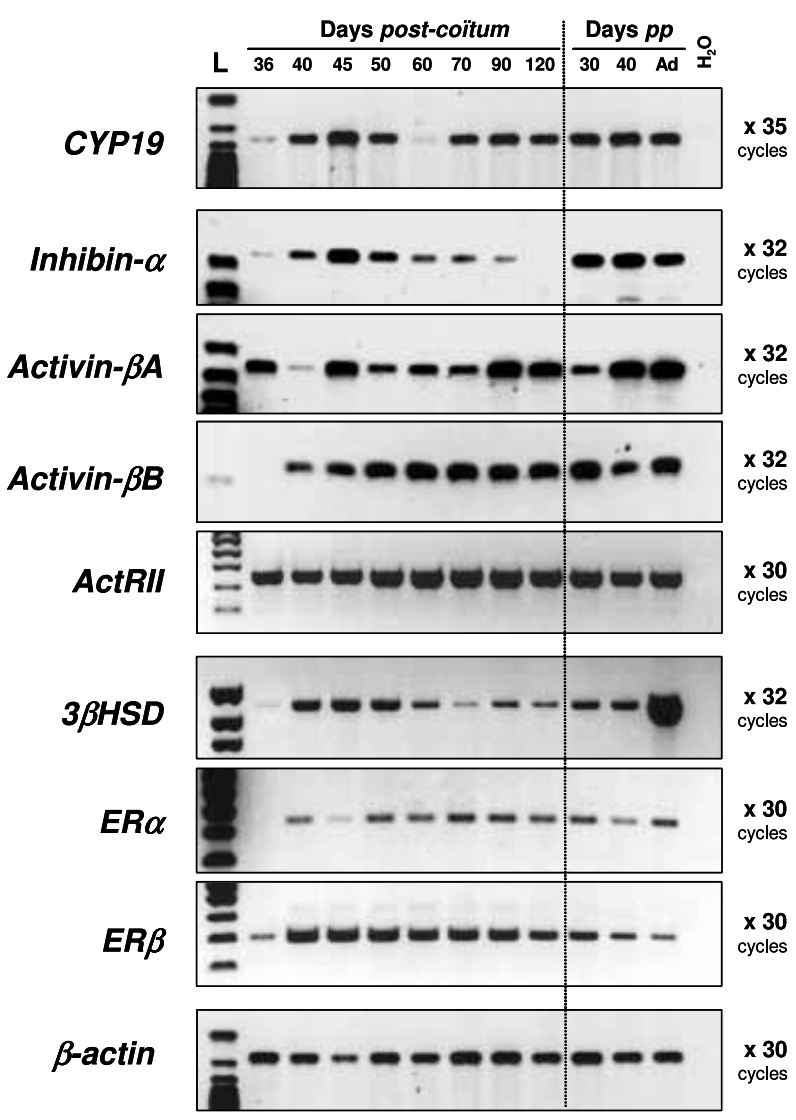

Figure 5 RT-PCR expression studies of the activin/inhibin system, $3 \beta H S D$ and both estrogen receptors during goat ovarian development. Note the peak of expression centred on $45 \mathrm{dpc}$ for inhibin- $\alpha$, activin- $\beta A$ and $3 \beta H S D$, similar to those observed for CYP19. ActRII, activin receptor II.

differentiation and maintenance, and the fact that Smad factors have previously been described as FOXL2 collaborators on the GRAS element (Ellsworth et al. 2003), the expression profiles of different members of the activin/inhibin system have been determined during goat ovarian development. By RT-PCR analyses, two subunits of the system, inhibin- $\alpha$ and activin- $\beta A$ showed an expression profile very similar to that found for CYP19. They were expressed between 36 and $55 \mathrm{dpc}$ with a peak at $45 \mathrm{dpc}$ (Fig. 5). The third subunit, activin- $\beta B$ and the activin receptor II are expressed at a high level from the first steps of ovarian differentiation (40 and $36 \mathrm{dpc}$ respectively) until adulthood (Fig. 5). Follistatin has also been tested and was expressed only after birth (data not shown), in agreement with previous studies performed in humans (Martins da Silva et al. 2004).

On the other hand, to confirm a physiological role of CTP19 in early ovarian development, expression of $3 \beta-H S D$ and estrogen receptors has also been analyzed (Fig. 5). The presence of $3 \beta-H S D$ transcripts between 36 and $55 \mathrm{dpc}$ is consistent with active steroidogenesis. Finally, these female steroids can induce some effects via their receptors ER $\alpha$ and ER $\beta$, which are both expressed from the first steps of ovarian differentiation (40 and 36 dpc respectively) until adulthood (Fig. 5).

In order to gain further insights into the physiological role of these genes, immuno-histological studies have been performed on $45 \mathrm{dpc}$ ovarian samples with different antibodies directed against inhibin- $\alpha$, activin$\beta A, E R \alpha, E R \beta$ and c-Kit, used as a germ cell marker. No signal was obtained for inhibin- $\alpha$ despite the fact that this antibody cross-reacts with the goat protein in fetal testes, confirming similar results observed in human and sheep (Braw-Tal et al. 1994, Martins da Silva et al. 2004). This absence of detectable inhibin- $\alpha$ protein in ovaries of different species, despite the presence of mRNA, could be a sign of the existence of a post-transcriptional regulatory process of this gene. No specific signal was observed for ER $\alpha$. These negative results can be due to the absence of a cross-reaction of the antibodies with the goat protein or to a too small quantity of protein, attested by the low level of transcripts detected by RT-PGR (Fig. 5). In contrast, ER $\beta$ can be detected and was expressed by all ovarian cellular types, somatic as well as germ cells (Fig. 6C). Interestingly, immuno-detection
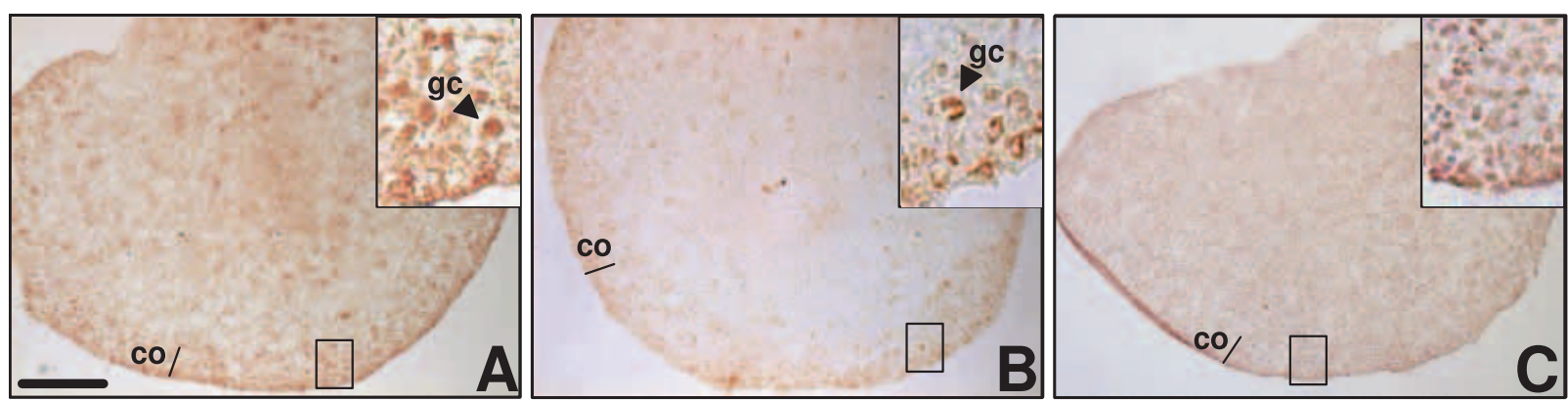

Figure 6 Activin $A(A)$, c-Kit $(B)$ and $\operatorname{ER} \beta(C)$ immunolocalization in a 45 dpc goat ovary. Higher magnification $(\times 4)$ of a positive cortical region (inside the rectangle) is presented in the upper right corner for each experiment. A line represents the thinness of the cortical region (co) where the majority of germ cells (gc) are located. Scale bar $200 \mu \mathrm{m}$. 
A

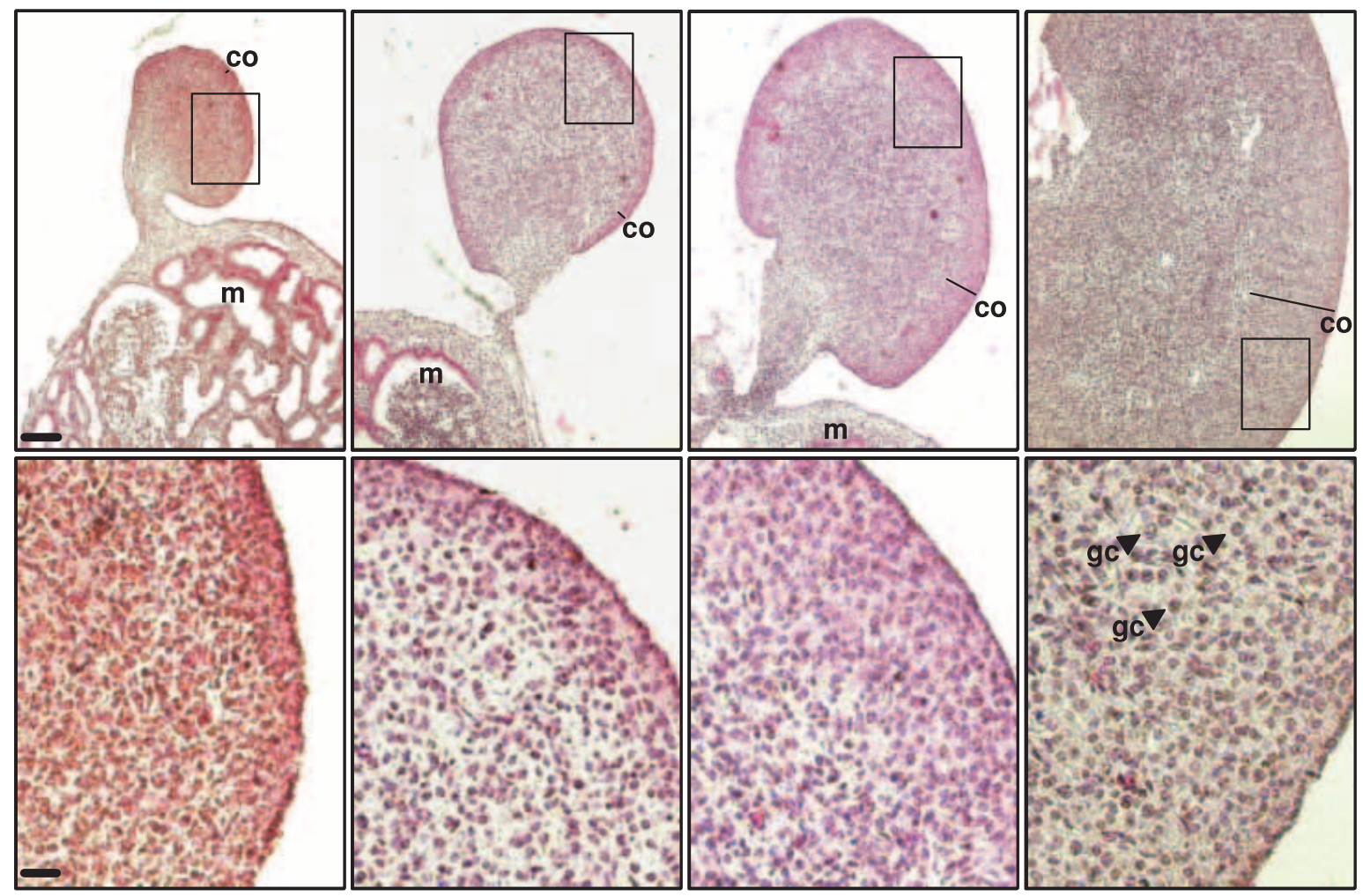

\section{B}

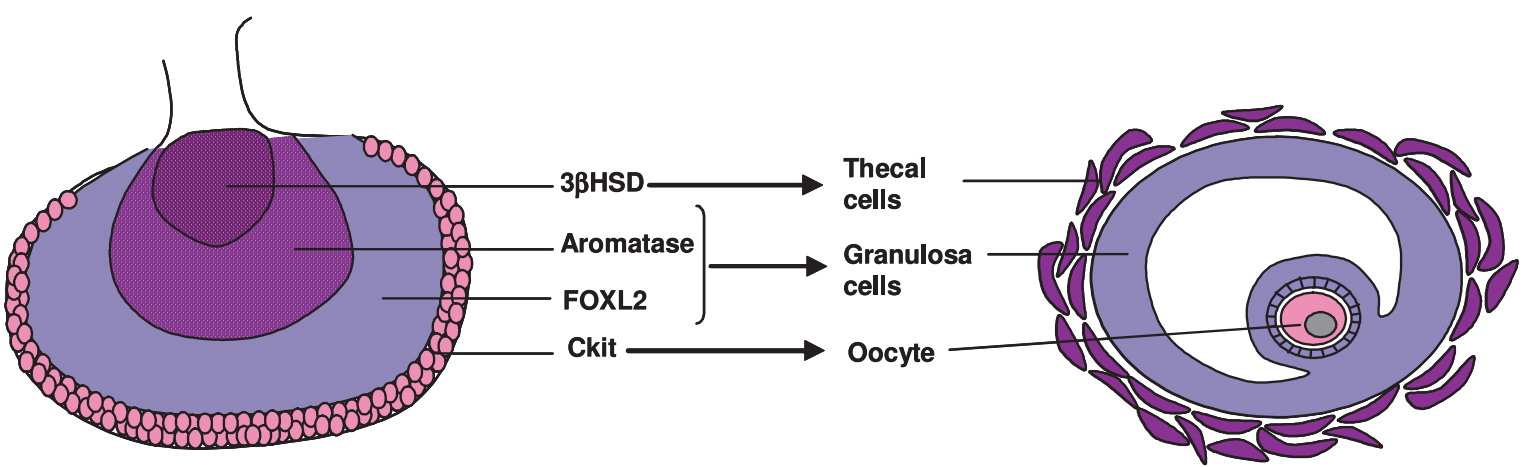

Figure 7 Ovarian development in goat during the 20-day period preceding germ cell meiosis. (A) Upper pictures: transverse sections of goat ovaries at $36,43,50$ and $56 \mathrm{dpc}$ respectively from left to right (m stands for mesonephros). Lower pictures present a fivefold magnification of the region encompassed in the upper rectangles. Note the crucial increase in the gonad during this period, especially in the cortical area (co) where germ cells (gc) are localized. Scale bars in upper pictures, $100 \mu$ m; in lower pictures, $20 \mu \mathrm{m}$. (B) Schematic representation of the 'inverse follicle' organization of the goat fetal ovary.

of activin- $\beta \mathrm{A}$ revealed a germ cell-specific expression (Fig. 6A), which is attested by the same cortical staining as those obtained for c-Kit (Fig. 6B). Once again, this result fits well with those reported in humans, showing that activin A promotes germ cell survival and proliferation before follicle formation (Martins da Silva et al. 2004).

\section{Discussion}

In the present study, experimental evidence showed that the CYP19 promoter 2 could represent a physiological target of FOXL2 during the early steps of goat ovary development. First, both proteins were found in the same cellular type located in the medulla of the $45 \mathrm{dpc}$ 
female gonads, around the rete ovari. Secondly, a direct transcriptional enhancing effect of FOXL2 on the CYP19 promoter 2 was reproducibly noticed in vitro, following co-transfection experiments in sheep primary granulosa cell cultures. Thirdly, a direct physical link between FOXL2 and the promoter of CYP19 could be established by chromatin immunoprecipitation. Altogether, these results reinforced the hypothesis that one of the roles of FOXL2 can be to enhance estrogen production during the early steps of ovarian differentiation in goats. This role has previously been envisaged by studying the ontogenesis of XX sex-reversal in PIS - /goat fetuses (Pailhoux et al. 2002, 2005). In this pathology, FOXL2 expression remained undetectable from the early stages of ovarian differentiation (34 dpc) and CYP19 expression has been found to be drastically decreased as the first consequence of downstream FOXL2 suppression, before SOX9 up-regulation and the occurrence of XX gonad sex-reversal.

\section{FOXL2 activates CYP19 promoter 2 in vitro and directly interacts with its promoter}

For the first time, our study provides clear evidence for FOXL2 being a potential transcriptional activator protein. Until now, two targets have been described for this recently characterized transcription factor, the GnRHR promoter via the GRAS composite regulatory element (Ellsworth et al. 2003), and the StAR promoter (Pisarska et al. 2004). This last study reported a repressive role of the native human FOXL2 protein on the StAR promoter containing numerous putative FOX-binding elements, a similar situation as those described here for the CYP19 promoter 2. The FOXL2 repressive activity was demonstrated in vitro by co-transfection experiments performed in Chinese hamster ovary $(\mathrm{CHO})$ cells. In this system, the authors found a $\sim 0 \cdot 5$-fold repression of FOXL2 on different lengths of the StAR promoter constructs. The StAR promoter was also tested in our primary granulosa cell system and a $\sim$ fivefold repression was noticeable with the goat FOXL2 native protein, confirming the reliability of our cellular system (S Fabre, unpublished observations). On the other hand, an enhancing effect of FOXL2 on the GnRHR gene in the pituitary was supposed (Ellsworth et al. 2003), but this effect was demonstrated with the use of a chimeric Foxl2-VP16 protein. This same chimeric construct was also needed to obtain an activation of CrP19 promoter 2 in COS7 cells. These results argued for FOXL2 being a weak transcriptional activator alone, thus requiring specific co-factors to induce a strong enhancing effect. This also seemed to be the case for CIP19 promoter 2 according to (i) the spatio-temporal profiles of both genes during ovarian development and (ii) the discrepancy of FOXL2 action depending on the cellular system used for transfection experiments (no effect in COS7 cells versus an enhancing effect in sheep granulosa cells).

\section{Estrogens are decisive in early ovarian development across vertebrates}

Estrogens play a crucial role in ovary differentiation in lower vertebrates, such as fishes, reptiles and birds. In these species, sex-reversal can be achieved by estrogen or anti-aromatase treatments leading to a steroidogenesis inversion. This steroid-responsiveness of gonad differentiation also exists in metatherian mammals, but has been lost in eutherian mammals, for which gonad development takes place in the uterus bathed in maternal hormones. In rainbow trout and chicken, FOXL2 expression profiles correlated with those of CYP19 during ovarian development, both in normal or sex-reversed situations (Baron et al. 2004, Govoroun et al. 2004, Hudson et al. 2005), but a direct regulatory role of FOXL2 on CIP19 transcription remains to be demonstrated in such species. Such a mechanism, pointed out in this study for the goat species, could represent a remnant of an ancestral mechanism. If this is true, it implies that FOXL2 could be one of the main factors acting in the early stages of ovary differentiation in lower vertebrates.

In goat, the first estrogen secretion occurred between the first step of gonad differentiation (36 dpc) and germ cell meiosis $(55 \mathrm{dpc})$. Interestingly, this $\sim 20$-day period in goat is restricted to a $\sim 1$-day period in mouse, between 12 and $13 \mathrm{dpc}$. During this period in the female mouse gonad, there is no active steroidogenesis, no CYP19 expression and, intriguingly, no Foxl2 protein. Indeed, Foxl2 was first detected around $13 \mathrm{dpc}$, when germ cell meiosis began in this species (Loffler et al. 2003, Pannetier et al. 2003). These observations reinforce the hypothesis that the primary switch controlling gonad differentiation could be different among mammals, especially between mouse and other mammals including human and goat. This species-specific difference should be taken into consideration for interpreting the phenotype discrepancy observed between XX goat $\mathrm{PIS}^{-{ }^{-}}$and XX mouse Foxl2 ${ }^{-1-}$.

In addition to this species-specific difference on steroidogenesis, the architectural organization of the female gonad also evolves differently between mouse and goat. During the $\sim 20$-day period preceding germ cell meiosis in goat, the cortical part of the ovaries considerably increases in size and a spatial organization into syncitial nests of germ cells intermingled with somatic cells takes place at $55 \mathrm{dpc}$ (Fig. 7A) (Pailhoux et al. 2002, Sawyer et al. 2002). Such an organization is not visible in the mouse ovary at the equivalent developmental stage (before $13.5 \mathrm{dpc}$ ) but occurs later, after $16 \cdot 5 \mathrm{dpc}$ (Appert et al. 1998). According to these observations and to published data on the proliferative effect of estrogens and activin A at later stages of ovary 
development, one could envisage a similar role of these molecules on both somatic and germ cells during these early stages of ovarian development in the goat. Indeed, it has been shown that activin A promotes germ cell survival and proliferation before primordial follicle formation in the human (Martins da Silva et al. 2004). Furthermore, an estradiol-induced mitogenic effect on prepubertal granulosa cells has also been reported in mouse (Robker \& Richards 1998, Dupont et al. 2000). Moreover, it has also been shown that activin A exerts a differential effect on steroid synthesis, by enhancing estradiol secretion and inhibiting progesterone production, in cultured goat or sheep granulosa cells (Shidaifat 2001, Shidaifat et al. 2001). Altogether, these observations and our results lead us to propose a model of early ovarian organization in goat.

\section{Early ovarian organization: towards a model of 'inverse follicle'}

At the beginning of their differentiation, before germ cells enter meiosis, the organization of goat ovaries evolves from an un-organized blastema to a regionalized gonad with a cortex and a medulla (Fig. 7A). Throughout this period, and by the use of molecular markers, our study demonstrates a centripetal organization of the goat ovaries. Indeed, $3 \beta H S D$ is expressed by a cellular population occupying a small circle in the deeper medulla, near the rete ovari. Cells expressing CYP19 are located within and around this first circle, and germ cells are located in the cortical region, just below the coelomic epithelium (Fig. 7B). Interestingly, this structure resembles that of an ovarian follicle except that the cell types are inversely located (centripetal versus centrifugal). Moreover, the same molecules seem to be used at these early stages for a cross-talk between somatic and germ cells. Indeed, one can postulate that activin A secreted by germ cells acts, in the first instance, as a proliferative factor on themselves via an autocrine pathway, and then as an estrogen-enhancer factor on cells located in the center of the gonad, via a paracrine action. In consequence, estrogens could reinforce the proliferative action on both germinal and somatic cells, both expressing ER $\beta$. Experiments are currently in progress in order to test the veracity of this model.

\section{Acknowledgements}

This manuscript is dedicated to the memory of Dr Pierre Mauléon, deceased on August 2004.

The authors wish to thank Caroline Vachias for technical assistance. Nathalie Servel and Bernard Vigier are also thanked for their help on classical histology. We are grateful to Colin M Clay (Colorado State University) for providing plasmid constructs, to Hajime Nawata
(Kyushu University) for providing KGN cells, and to Céline Guigon for providing ER $\beta$ antibodies. This project was supported by the French Ministry of Research (ACI-Jeunes Chercheurs, JC5339). M P is the recipient of a fellowship from the Fondation pour la Recherche Médicale. F B is the recipient of a CIFRE fellowship from Pfizer. The authors declare that there is no conflict of interest that would prejudice the impartiality of this scientific work.

\section{References}

Appert A, Fridmacher V, Locquet O \& Magre S 1998 Patterns of keratins 8,18 and 19 during gonadal differentiation in the mouse: sex- and time-dependent expression of keratin 19. Differentiation $63273-284$.

Baron D, Cocquet J, Xia X, Fellous M, Guiguen Y \& Veitia RA 2004 An evolutionary and functional analysis of FoxL2 in rainbow trout gonad differentiation. Fournal of Molecular Endocrinology $33705-715$.

Braw-Tal R, Tisdall DJ, Hudson NL, Smith P \& McNatty KP 1994 Follistatin but not alpha or beta A inhibin subunit mRNA is expressed in ovine fetal ovaries in late gestation. Fournal of Molecular Endocrinology 13 1-9.

Bulun SE, Takayama K, Suzuki T, Sasano H, Yilmaz B \& Sebastian S 2004 Organization of the human aromatase p450 (CYP19) gene. Seminars in Reproductive Medicine 22 5-9.

Burns RK 1955 Experimental reversal of sex in the gonads of the opossum Didelphis virginiana. PNAS 41 669-676.

Caburet S, Demarez A, Moumne L, Fellous M, De Baere E \& Veitia RA 2004 A recurrent polyalanine expansion in the transcription factor FOXL2 induces extensive nuclear and cytoplasmic protein aggregation. Fournal of Medical Genetics 41 932-936.

Carlsson P \& Mahlapuu M 2002 Forkhead transcription factors: key players in development and metabolism. Developmental Biology $2501-23$.

Cocquet J, Pailhoux E, Jaubert F, Servel N, Xia X, Pannetier M, De Baere E, Messiaen L, Cotinot C, Fellous M \& Veitia RA 2002 Evolution and expression of FOXL2. Fournal of Medical Genetics 39 916-921.

Conley A \& Hinshelwood M 2001 Mammalian aromatases. Reproduction 121 685-695.

Couse JF, Hewitt SC, Bunch DO, Sar M, Walker VR, Davis BJ \& Korach KS 1999 Postnatal sex reversal of the ovaries in mice lacking estrogen receptors alpha and beta. Science 286 2328-2331.

Coveney D, Shaw G \& Renfree MB 2001 Estrogen-induced gonadal sex reversal in the tammar wallaby. Biology of Reproduction 65 613-621.

Crisponi L, Deiana M, Loi A, Chiappe F, Uda M, Amati P, Bisceglia L, Zelante L, Nagaraja R, Porcu S, Ristaldi MS, Marzella R, Rocchi M, Nicolino M, Lienhardt-Roussie A, Nivelon A, Verloes A, Schlessinger D, Gasparini P, Bonneau D, Cao A \& Pilia G 2001 The putative forkhead transcription factor FOXL2 is mutated in blepharophimosis/ptosis/epicanthus inversus syndrome. Nature Genetics 27 159-166.

De Baere E, Beysen D, Oley C, Lorenz B, Cocquet J, De Sutter P, Devriendt K, Dixon M, Fellous M, Fryns JP, Garza A, Jonsrud C, Koivisto PA, Krause A, Leroy BP, Meire F, Plomp A, Van Maldergem L, De Paepe A, Veitia R \& Messiaen L 2003 FOXL2 and BPES: mutational hotspots, phenotypic variability, and revision of the genotype-phenotype correlation. American Fournal of Human Genetics 72 478-487.

Dupont S, Krust A, Gansmuller A, Dierich A, Chambon P \& Mark M 2000 Effect of single and compound knockouts of estrogen 
receptors alpha (ERalpha) and beta (ERbeta) on mouse reproductive phenotypes. Development 127 4277-4291.

Elbrecht A \& Smith RG 1992 Aromatase enzyme activity and sex determination in chickens. Science 255 467-470.

Ellsworth BS, Burns AT, Escudero KW, Duval DL, Nelson SE \& Clay GM 2003 The gonadotropin releasing hormone $(\mathrm{GnRH})$ receptor activating sequence (GRAS) is a composite regulatory element that interacts with multiple classes of transcription factors including Smads, AP-1 and a forkhead DNA binding protein. Molecular and Cellular Endocrinology 206 93-111.

Fadem BH \& Tesoriero JV 1986 Inhibition of testicular development and feminization of the male genitalia by neonatal estrogen treatment in a marsupial. Biology of Reproduction 34 771-776.

Fisher CR, Graves KH, Parlow AF \& Simpson ER 1998 Characterization of mice deficient in aromatase (ArKO) because of targeted disruption of the Cyp19 gene. PNAS 95 6965-6970.

Furbass R, Kalbe C \& Vanselow J 1997 Tissue-specific expression of the bovine aromatase-encoding gene uses multiple transcriptional start sites and alternative first exons. Endocrinology 138 2813-2819.

Ghosh S, Wu Y, Li R \& Hu Y 2005 Jun proteins modulate the ovary-specific promoter of aromatase gene in ovarian granulosa cells via a cAMP-responsive element. Oncogene 24 2236-2246.

Govoroun MS, Pannetier M, Pailhoux E, Cocquet J, Brillard JP, Couty I, Batellier F \& Cotinot C 2004 Isolation of chicken homolog of the FOXL2 gene and comparison of its expression patterns with those of aromatase during ovarian development. Developmental Dynamics 231 859-870.

Guiguen Y, Baroiller JF, Ricordel MJ, Iseki K, Mcmeel OM, Martin SA \& Fostier A 1999 Involvement of estrogens in the process of sex differentiation in two fish species: the rainbow trout (Oncorhynchus mykiss) and a tilapia (Oreochromis niloticus). Molecular Reproduction and Development 54 154-162.

Hasegawa T, Zhao L, Caron KM, Majdic G, Suzuki T, Shizawa S, Sasano H \& Parker KL 2000 Developmental roles of the steroidogenic acute regulatory protein (StAR) as revealed by StAR knockout mice. Molecular Endocrinology 14 1462-1471.

Hayes TB \& Menendez KP 1999 The effect of sex steroids on primary and secondary sex differentiation in the sexually dichromatic reedfrog (Hyperolius argus: Hyperolidae) from the Arabuko Sokoke Forest of Kenya. General and Comparative Endocrinology 115 188-199.

Hudson QJ, Smith CA \& Sinclair AH 2005 Aromatase inhibition reduces expression of FOXL2 in the embryonic chicken ovary. Developmental Dynamics 233 1083-1090.

Ikeda Y, Shen WH, Ingraham HA \& Parker KL 1994 Developmental expression of mouse steroidogenic factor-1, an essential regulator of the steroid hydroxylases. Molecular Endocrinology 8 654-662.

Kaufmann E \& Knochel W 1996 Five years on the wings of fork head. Mechanisms of Development 57 3-20.

Krisfalusi M \& Cloud JG 1999 Gonadal sex reversal in triploid rainbow trout (Oncorhynchus mykiss). Fournal of Experimental Zoology 284 466-472.

Le Bellego F, Pisselet C, Huet C, Monget P \& Monniaux D 2002 Laminin-alpha 6 betal integrin interaction enhances survival and proliferation and modulates steroidogenesis of ovine granulosa cells. Fournal of Endocrinology 172 45-59.

Lenz S, Pohland R, Becker F \& Vanselow J 2004 Expression of the bovine aromatase cytochrome $\mathrm{P} 450$ gene (Cyp19) is primarily regulated by promoter 2 in bovine follicles and by promoter $1 \cdot 1$ in corpora lutea. Molecular Reproduction and Development 67 406-413.

Loffler KA, Zarkower D \& Koopman P 2003 Etiology of ovarian failure in blepharophimosis-ptosis-epicanthus inversus syndrome: FOXL2 is a conserved, early-acting gene in vertebrate ovarian development. Endocrinology 144 3237-3243.

Martins da Silva SJ, Bayne RA, Cambray N, Hartley PS, McNeilly AS \& Anderson RA 2004 Expression of activin subunits and receptors in the developing human ovary: activin A promotes germ cell survival and proliferation before primordial follicle formation. Developmental Biology 266 334-345.

Mauléon P, Bézard J \& Terqui M 1977 Very early and transient $17 \beta$-estradiol secretion by fetal sheep ovary. In vitro study. Annales de Biologie Animale, Biochimie et Biophysique 17 399-401.

Nishi Y, Yanase T, Mu Y, Oba K, Ichino I, Saito M, Nomura M, Mukasa C, Okabe T, Goto K, Takayanagi R, Kashimura Y, Haji M \& Nawata H 2001 Establishment and characterization of a steroidogenic human granulosa-like tumor cell line, KGN, that expresses functional follicle-stimulating hormone receptor. Endocrinology 142 437-445.

Pailhoux E, Vigier B, Chaffaux S, Servel N, Taourit S, Furet JP, Fellous M, Grosclaude F, Cribiu EP, Cotinot C \& Vaiman D 2001 An 11.7-kb deletion triggers intersexuality and polledness in goats. Nature Genetics 29 453-458.

Pailhoux E, Vigier B, Vaiman D, Servel N, Chaffaux S, Cribiu EP \& Cotinot C 2002 Ontogenesis of female-to-male sex-reversal in XX polled goats. Developmental Dynamics 224 39-50.

Pailhoux E, Vigier B, Schibler L, Cribiu EP, Cotinot C \& Vaiman D 2005 Positional cloning of the PIS mutation in goats and its impact on understanding mammalian sex-differentiation. Genetics Selection Evolution 37 Suppl 1 55-64.

Pannetier M, Servel N, Cocquet J, Besnard N, Cotinot C \& Pailhoux E 2003 Expression studies of the PIS-regulated genes suggest different mechanisms of sex determination within mammals. Cytogenetics and Genome Research 101 199-205.

Pannetier M, Renault L, Jolivet G, Cotinot G \& Pailhoux E 2005 Ovarian-specific expression of a new gene regulated by the goat PIS region and transcribed by a FOXL2 bidirectional promoter. Genomics 85 715-726.

Payen E, Pailhoux E, Abou Merhi R, Gianquinto L, Kirszenbaum M, Locatelli A \& Cotinot C 1996 Characterization of ovine SRY transcript and developmental expression of genes involved in sexual differentiation. International Fournal of Developmental Biology $40567-575$.

Pieau C, Dorizzi M \& Richard-Mercier N 1999 Temperaturedependent sex determination and gonadal differentiation in reptiles. Cellular and Molecular Life Science 55 887-900.

Pierre A, Pisselet C, Dupont J, Mandon-Pepin B, Monniaux D, Monget P \& Fabre S 2004 Molecular basis of bone morphogenetic protein-4 inhibitory action on progesterone secretion by ovine granulosa cells. Fournal of Molecular Endocrinology 33 805-817.

Pisarska MD, Bae J, Klein C \& Hsueh AJ 2004 Forkhead 12 is expressed in the ovary and represses the promoter activity of the steroidogenic acute regulatory gene. Endocrinology 145 3424-3433.

Quirke LD, Juengel JL, Tisdall DJ, Lun S, Heath DA \& McNatty KP 2001 Ontogeny of steroidogenesis in the fetal sheep gonad. Biology of Reproduction 65 216-228.

Robker RL \& Richards JS 1998 Hormonal control of the cell cycle in ovarian cells: proliferation versus differentiation. Biology of Reproduction 59 476-482.

Sawyer HR, Smith P, Heath DA, Juengel JL, Wakefield SJ \& McNatty KP 2002 Formation of ovarian follicles during fetal development in sheep. Biology of Reproduction 66 1134-1150.

Scheib D 1983 Effects and role of estrogens in avian gonadal differentiation. Differentiation 23 S87-S92.

Schmidt D, Ovitt CE, Anlag K, Fehsenfeld S, Gredsted L, Treier AC \& Treier M 2004 The murine winged-helix transcription factor Foxl2 is required for granulosa cell differentiation and ovary maintenance. Development $131933-942$.

Shidaifat F 2001 Effect of activin-A on goat granulosa cell steroidogenesis. Theriogenology 56 591-599.

Shidaifat F, Khamas W \& Hailat N 2001 Activin-A differentially regulates steroidogenesis by sheep granulosa cells. Research in Veterinary Science 71 23-25.

Uda M, Ottolenghi C, Crisponi L, Garcia JE, Deiana M, Kimber W, Forabosco A, Cao A, Schlessinger D \& Pilia G 2004 Foxl2 
disruption causes mouse ovarian failure by pervasive blockage of follicle development. Human Molecular Genetics 13 1171-1181.

Vanselow J, Zsolnai A, Fesus L, Furbass R \& Schwerin M 1999 Placenta-specific transcripts of the aromatase encoding gene include different untranslated first exons in sheep and cattle. European Fournal of Biochemistry 265 318-324.

Wade J \& Arnold AP 1996 Functional testicular tissue does not masculinize development of the zebra finch song system. PNAS 93 5264-5268.
Wang D, Kobayashi T, Zhou L \& Nagahama Y 2004 Molecular cloning and gene expression of Foxl2 in the Nile tilapia,

Oreochromis niloticus. Biochemical and Biophysical Research Communications 320 83-89.

Received in final form 3 February 2006

Accepted 17 February 2006

Made available online as an Accepted Preprint 21 February 2006 